\title{
Empowerment Needs of Women With Breast Cancer: A Qualitative Study
}

\author{
Fariba Taleghani ${ }^{1}$; Masoud Bahrami ${ }^{1}$; Marzeyeh Loripoor ${ }^{1, *}$; Alireza Yousefi $^{2}$ \\ ${ }^{1}$ School of Nursing and Midwifery, Nursing and Midwifery Care Research Center, Isfahan University of Medical Sciences, Isfahan, IR Iran \\ ${ }^{2}$ Medical Education Research Center, Isfahan University of Medical Sciences, Isfahan, IR Iran \\ ${ }^{*}$ Corresponding Author: Marzeyeh Loripoor, School of Nursing and Midwifery, Nursing and Midwifery Care Research Center, Isfahan University of Medical Sciences, Isfahan, IR Iran. \\ Tel:+98-3915225900, E-mail: marzeyehloripoor@yahoo.com
}

Received: November 24, 2013; Revised: January 24, 2014; Accepted: March 5, 2014

\begin{abstract}
Background: Due to the increasing number of women suffering from breast cancer worldwide, promoting the empowerment of these patients is an important factor affecting their survival.

Objectives: Few studies have investigated the empowerment needs of the breast cancer women, especially in Iran. Therefore, this study was performed to explain the empowerment needs of women with breast cancer in Iran.

Patients and Methods: In this qualitative study, 19 women with breast cancer were interviewed regarding their empowerment needs using the individual open-ended and, in-depth interviews and then the qualitative data were analyzed through content analysis.

Results: Three main categories of empowerment needs from the participants' perspectives were as follows: 1- information: the initial empowerment plans (timely and comprehensive information, coordination and continuity of information, easy and full-time access to information), 2- beliefs: the approval of the empowerment plans for execution (actuality, trust and hope and new beliefs), and 3- skills: efficient execution of the empowerment plans (communication skills, expression the needs, emotions, questions and use of the internet). Conclusions:It seems that promoting the empowerment of women with breast cancer is essential. Factors found in this study and also in similar studies, in which empowerment needs are explained in-depth through the experiences of the patients, should be considered and used in the treatment, educational and counseling programs to promote the empowerment of women with breast cancer.
\end{abstract}

Keywords: Empowerment; Breast Cancer; Women; Iran

\section{Background}

Breast cancer is the most common cancer among women. According to the World Health Organization report, more than 1.2 million people are diagnosed with breast cancer annually (1). In Iran, breast cancer is also ranked first among cancers (2). Mean age of women at the time of diagnosis in Iran is 10 years lower than that in Western countries (3). Iranian women experience this disease between ages of 35 and 44 years (4). However, survival of breast cancer patients has increased in recent years in younger groups (5).

Therefore, a relatively large group of mostly young women spend the significant portions of their lives with breast cancer, which requires long-term treatments including surgery, chemotherapy, or radiotherapy leading to some severe complications $(6,7)$. Women with breast cancer spend the most important years of their life with numerous physical, sexual, and psycho-social complications induced by the disease and its treatments in women who suffer from their damaged identity and femininity because of the disease (8-13) prepare the grounds for feeling of inability and loss of control over their life (14, 15). Feeling of inability and loss of control may inversely affect the process of recovery and hinder reconstruction of a normal life (16). Therefore, one of the biggest chal- lenges for women with breast cancer is to gain competence and ability to control their life (17) and thus they can manage the current situation and benefit from other empowerment outcomes and feeling of control over life such as making changes, hope in the future and positive self-esteem (18). Empowerment also leads to access to high quality and proper care (19), enhanced quality of life, accountability, better interaction with medical staff, satisfaction (20), better response to treatment (21, 22), preventing the complications (23), and developing apositive attitude toward the disease (24). It is expected that the increased patient empowerment can reduce the need for support of the healthcare system, and consequently, it can reduce healthcare $(25,26)$ and treatment $(27)$ costs. Given the important role of women in development, empowering women affected by breast cancer, as a relatively large group, is essential in sustainable development of a country. Empowerment has applications in different areas, and human life improvement is central in every area (28). Many definitions have been provided for empowerment (29) and most include personal control, self-efficacy, and self-control (24,30-35). Empowerment of patients is a process in which the patient mobilizes and increases her resources and thus finds the ability to control her life, 
meet her needs, and solve problems (36). An empowered patient is an informed patient that takes responsibility for her health as much as possible (37). Empowering patient in health care means promoting self-regulation and self-determination to achieve maximum well-being and health (38). Despite various definitions and studies in the area of empowerment, its concept is still vague (39), and achieving clarity requires further research into this area. In most studies conducted to clarify this concept in relation to health care and in chronic diseases like cancer, it has been investigated from the experts' perspective, and the patients' perspective has less been considered (32). Meanwhile, the feeling of control over the disease and empowerment is a totally unique experience in cancer patients, and cancer patients have different ideas about what causes their empowerment $(40,41)$. In this respect, Gibson, quoting Rappaport, states that empowerment should be defined by intended people (42). In other words, the most effective way to define empowerment is to ask cancer patients themselves how empowerment can be achieved for them. Results of the study by Bulsara et al. (2004) that investigated empowerment from the perspective of patients with leukemia emphasize the fact that empowerment strategies, capability to fight cancer, decision making, receiving support of the family members and significant others, overcoming denial, anger, anxiety about future are all means of accepting cancer and seeking ways to control the situation (40). Furthermore, to clarify empowerment in a particular group of patients, it is best to ask them about it. It is believed that concept of empowerment is affected by particular population and background (28), and to define it, it is better to define this concept in each specific background separately. In a society with religious and cultural beliefs like Iranian society, in which family is considered sacred, women are dedicated to their husband and children and with added huge role in developmental transition, empowerment of women can have a different meaning altogether (43).

\section{Objectives}

In relation to empowerment in women with breast cancer, especially from their own perspective, very few studies have been conducted, and none of them were found in Iran. This qualitative study was conducted to explain the empowerment needs of women with breast cancer.

\section{Patients and Methods}

This qualitative study was conducted through the conventional content analysis in Isfahan, Iran. Qualitative study is more used for subjects that are less understandable with quantitative methods and sufficient data are not available for them (44). Since sufficient data on empowerment of women with breast cancer do not exist, especially in Iran, and due to the multi-faceted and complex nature of empowerment, qualitative approach was used in the present study, so that, deeper understanding of participants' experiences of empowerment in this period can be achieved through their free expression of feelings, behaviors, and experiences. Prior to collection of data, and after approval of the proposal by the research council of Isfahan University of Medical Sciences (approval number: 391304), permission to enter the clinic was obtained from ethics committee of Isfahan University of Medical Sciences and hospital and clinic authorities. To comply with ethical considerations, participants were informed about objectives and importance of the study prior to conducting interviews, and took part with informed consent. Interviews were recorded with their permission and they were assured of confidentiality of data. Participants were also informed that they could withdraw from the study at any stage they wished and that their details would remain confidential. In this study, a maximum variation sampling strategy was used. This meant that participants were selected from women with breast cancer referred to special cancer hospital and chemotherapy clinic in different age groups, levels of income and education, and socio-economic classes. Study inclusion criteria were lack of obvious metastases, no previous cases of mental illness, no history of cancer or other chronic diseases, minimum of one year after diagnosis, not in the final stages of disease, and willingness to take part in the study and share experiences. With participants' agreement, face-to-face interviews were conducted in the hospital, at home, or any place preferred by the participant. All interviews were conducted by a research team member, familiar with interviewing techniques. Sampling was continued until the saturation of data, and accordingly, 19 patients took part in the study, accepted invitation to interview, and remained until the end of study. To collect data, the non-structured, individualopen-ended and indepth interviews were performed. Initially, the following general questions were asked as the interview guide: In your opinion, what does empowerment mean in this period, and who do you consider empowered? What induces feeling of empowerment in you in this period? and, in your experience, what are the empowerment needs? These entailed open and interpretive responses, and then, participants' answers would guide the process of interview and questions. With permission and consent of the participants, interviews were recorded. Duration of interviews varied from 30 to 90 minutes, and the number of interviews varied from 1 to 3 times. Immediately after recording each interview, the researcher listened to the interview repeatedly, and after grasping an overall impression, the interview was written down verbatim, and analysis unit took shape. Then the texts were also repeatedly read line by line, and the important statements were determined and underlined, and their gist was coded. Interviews were coded by three research team members separately, and codes agreed upon in meetings of these team members were merged and initial sub-categories were formed. Codes resulting from new interviews were 
included in these sub-categories, and new sub-categories thus emerged. Assessment of relationships between interviews, codes, and sub-categories led to modification of sub-categories and formation of the final category.

To ensure accuracy and reliability of qualitative data, scientific rigor criteria of Guba (45) and Lincoln (46) were used including credibility, dependability, transferability and confirm-ability. Methods of determining credibility, including review by participants and examination of data by expert colleagues were used. Reliability was enhanced through constant comparative analysis, return to the field (site), and allocation of sufficient time, and constant ongoing communication with participants and presence in the field. To obtain richer data, efforts were made to provide good rapport and friendly and trusting atmosphere for participants. For proportionality, the maximum variation sampling technique was used. Also, confirm ability of findings was assessed through the control of the external observers familiar with qualitative research. To this end, parts of interview texts, together with relevant codes and emerged categories were examined and confirmed by two experts familiar with qualitative research. For dependability of research, the researcher accurately recorded and reported stages and processes of the study, so that others could follow-up research.

\section{Results}

Data collected through interviewing 19 women with breast cancer were studied. Table 1 presents the characteristics of the participating women. Qualitative content analysis of data obtained through interviewing with participants about their empowerment needs led to formation of 3 main categories as follows: 1) information: the initial empowerment plan, 2) beliefs: approval of the plan for execution and 3) skills: effective execution of plan. These beliefs, skills and information were partly derived from the person, and partly from interaction with others. All of the participants believed that empowerment was an important factor during the disease period (Table 2).

\subsection{Information: Initial Empowerment Plan}

\subsubsection{Timely and Comprehensive Information}

Receiving comprehensive information that covered all their needs on time and was provided before entering each stage of the disease and its treatment was important to empowerment. Among information needs for the empowerment cited by these women were the relevant information to breast cancer and treatment options, prognosis and recurrence of disease, treatment complications and ways to prevent and reduce them, relevant exercises, diet in this period, lymphedema and its treatment, breast reconstruction, self-care, NGOs associated with breast cancer and peer groups and how to participate in them, and sexual counseling and information."To know what your illness is, what stage of the disease you are in, what are survival chances, things you should do to enhance your chances, things that give you the power and you feel you are doing something to survive". "I didn't know that physiotherapy was for us at all, otherwise my arm wouldn't be like this. It can't be fixed. Nobody tells us anything at all".

\subsubsection{Continuous and Coordinated Information}

According to the participants' experience, sometimes information received from different sources is incomplete and even inconsistent, which confuses patients. Most of the information that the patients received continues only until the end of the treatment, and afterwards no specific source of information and care was introduced, and patient felt she had been left unsupported."Here, someone would tell me to eat this and someone else would suggest that I should eat anything I want and that it had nothing to do with what I ate. After surgery, another doctor would say, why have they removed your breast in this way, there was no need at all, and another one says I should do this test, and someone else would say, no there is no need. You wonder what is right and what is wrong". "When your treatment is over, even this bits and pieces of information you used to receive is stopped. They should at least give us something that is useful for years to come".

\subsubsection{Easy and Full-time Access to Information}

Patients believed that a 24-hour source of information was effective to respond to the questions and problems associated with their disease and to prevent feeling of inadequacy. Since patients could use this to ask questions they felt too shy to ask face-to-face, like sexual matters, and the like. "I wish anytime we had a question there was someone to answer it. Sometimes, when you have a problem, you never know whom or where to contact".

\subsection{Beliefs: Approving and Equipping Empower- ment Plan for Execution}

Women's beliefs were among the important and influential cases for the empowerment of these women.

\subsubsection{Accepting the Truth}

Some participants expressed envy toward their peers who had accepted their disease and lived with it like anything else they had. These patients that had problem with their cancer considered their peers more empowered. "I know a lady that believes her cancer is a part of her, just like other things she has. Good for her, she lives in peace. How can cancer be a part of someone? I wish I were like that, but I don't think I can".

\subsubsection{Faith and Hope}

One of the important beliefs was faith in God, medical 
team, and oneself. This kept hope alive in their hearts. Faith in God, on the basis that decrees and breast cancer are God's benevolence, expedience, and test gives them a special power to live and motivation to pass the divine test with flying colors."You know, when you see people like yourself, the sense of loneliness and incapability reduces, especially such strongwomen, it is as if they never had cancer and their breast had never been taken off, God bless them".Sometimes patients had experienced the relationships that were with pity or even stigma, which were annoying and hurt their empowerment. Participants believed that the skill to properly deal with such relationships was necessary for empowerment. To avoid these problems, some people had resorted to hiding their disease from others, and only one or two had decisively dealt with these relationships."When they hear about it, they either cry in front of you, or they may even say behind your back, "she deserved it", “I don't have to tell anyone".

\subsection{Skills: Effective Execution of Empowerment Plan}

\subsubsection{Ability to Express Feelings, Needs, and Questions}

This was a skill that patients rather needed in this period. Accumulation and suppression of these cases had gradually strengthened the feelings of indifference and passivity in them.

"To be able to talk about your feelings without having to pretend that everything is $\mathrm{OK}$ and there is no problem takes the pressure off of you. After all, you have been through a lot and cannot be like before".

\subsubsection{Use of the Internet}

Participants who were able to use the internet had obtained large amounts of their information needs in this way, and appeared to be more empowered than others. One of the participants was a member of the internet breast cancer support network. "Now I'm able to obtain information I need on the net; about diet, treatment, and questions I may have. When I'm feeling down, I search for things I like; it comforts me. But, poor things, not many people know how to".

\section{Discussion}

In this study, in the experience of breast cancer patients, having information, beliefs, and specific skills were considered as the underlying factors for empowerment despite breast cancer. Although these factors are categorized, they are linked like rings on a chain, affect one another, and are influenced by one another. Like the results obtained in this study, several other studies have confirmed the need for information in the empowerment and impact on health (32). This means that, with sufficient information, patients feel responsible for promotion of their own health and quality of life (37). Funnel et al. considered taking informed decision, proper self-control, and understanding the right condition to execute the decision, dependent on having information (38).

\begin{tabular}{|c|c|c|c|c|c|c|}
\hline Participant & Age, $y$ & Education & Marital Status & Occupation & Place of Residence & Religion \\
\hline 1 & 34 & diploma & married & housewife & city & Islam \\
\hline 2 & 38 & degree & married & housewife & city & Islam \\
\hline 3 & 34 & degree & married & teacher & city & Islam \\
\hline 4 & 46 & diploma & married & housewife & city & Islam \\
\hline 5 & 42 & junior high & married & housewife & village & Islam \\
\hline 6 & 40 & junior high & married & hospital service & village & Islam \\
\hline 7 & 35 & diploma & married & housewife & city & Islam \\
\hline 8 & 38 & bachelor's & married & midwife & city & Islam \\
\hline 9 & 64 & senior high & married & housewife & city & Islam \\
\hline 10 & 38 & diploma & married & housewife & city & Islam \\
\hline 11 & 55 & diploma & married & housewife & city & Islam \\
\hline 12 & 53 & higher diploma & married & teacher & city & Islam \\
\hline 13 & 43 & junior high & married & housewife & village & Islam \\
\hline 14 & 43 & diploma & married & housewife & city & Islam \\
\hline 15 & 43 & bachelor's & married & teacher & city & Islam \\
\hline 16 & 60 & diploma & married & housewife & city & Islam \\
\hline 17 & 40 & diploma & married & housewife & city & Islam \\
\hline 18 & 42 & bachelor's & married & office worker & city & Islam \\
\hline 19 & 40 & bachelor's & married & nurse & city & Islam \\
\hline
\end{tabular}


Table 2. Categories and Sub-Categories of Empowerment Needs With Presence of Breast Cancer ${ }^{\text {a }}$

1) Information: initial empowerment plan

Timely and comprehensive information (14-17.2\%)

Continued and coordinated information (9-11.1\%)

Easy and full-time access to information (7-8.6\%)

2) Beliefs: approval and equipping the empowerment plan for execution

Accepting the truth (7-8.6\%)

Trust and hope (faith in God, medical team, and one-self) (14-17.2\%)

New beliefs (6-7.4\%)

3) Skills: effective execution of empowerment plan

Communicational skills (the appropriate reaction skill to improper relationships, skill to communicate with family members, medical team, relationship with others and peer) (12-14.8\%)

Skills for expressing needs, emotions, and questions (9-11.1\%)

Internet use skills (3-3.7\%)

${ }^{\mathrm{a}}$ Numbers in brackets represent number of codes extracted and their percentage of involvement in formation of subtheme.

In fact, empowerment of patient begins with obtaining information and education (47). Thus, it is called the initial empowerment plan. However, the education, as shown by the results of this study, especially in chronic diseases requires continuity. In a study by Gould, 2009, after completion of treatment, patient information and support had been discontinued, and the patient did not know where to go for information and support (48). This is in line with the results obtained in this study. The relationship between discontinuity of information and support with patient's feeling of incapability is also confirmed in the study by Paterson (49). New beliefs that had been created or strengthened in patients after cancer in this study were important in accepting the truth and empowerment. Results of a study by Moc et al. showed that in the opinion of breast cancer patients, changes in thinking are important in the process of empowerment (50). In the study by Moc one of the stages of the process of empowerment in cancer patients is the new definition and interpretation of the disease, which helps them to accept (51).

In this study, trust in God, the medical team, and also in oneself, and the hope induced by this trust played an important role in their empowerment. Many studies have shown the relationship between spirituality and positive adjustment to cancer and mental health (52-58). Participants in this study considered trust in the doctor and medical team rather due to understanding their thoughts and feelings, than involvement in medical decisions. Some studies have shown that patient's trust is effectively dependent on communicational behavior of the doctor (59-62). In the study by Aujoulat and d'Hoore patients felt empowered when they could ask questions (32). In a study by Arora et al. emotional support was the most important determining factors in patient trust (63). Emotional support and listening to the patient is in fact, confirmation of patient's identity, irrespective of the disease; and participants in this study also were unhappy about attention to their disease rather than to themselves, and considered it a factor in creating sense of inability. Paterson et al. feeling of incapability is also confirmed in the study by Paterson argued that distinction between the person and the disease occurs when patient tries to explain her disease and have control over it (64). This is an important step toward empowerment because it enables the person to perceive herself as a subject, not an object in the process of disease, and naturally, attention to patient's explanation helps this process. In this respect, Stanhope and Lancaster believes that professional people are not necessarily required to resolve patient's problems and emotions to gain patient's trust, but by providing an ambience in which patient can express her emotions can help resolve the issue (65). In fact, patient's trust is hidden in the answer to the question that "are you perceived as a person?" (66). Perhaps, the reason for participants considering involvement in medical decisions less important in empowerment is that they have been less involved or rarely involved in decision making and are not aware of their rights in this respect, and that they follow the traditional view induced by the medical system that they know better than you do (67), and that decision is only theirs. Trust and confidence in oneself was one of the cases that were considered important in empowerment. People that have confidence in their own abilities, consider crisis as a challenge, and believe they can control threatening situations. Such understandings of capabilities, which is called self-efficacy (68) leads to reduction in stress and depression, performing responsibilities and enhanced quality of life in breast cancer patients (69) and strongly affect positive behavior and adjustment (70). Pointing out relationships was frequently present in participants' statements, which showed strong effect of this factor on patient's emotions and experiences. Gibson believes empowerment is facilitated through 
interaction (36). In the study by Mok et al. on the concept of empowerment in the view of the cancer patients, empowerment is a process in which patients feel strong on the inside in relationships with people around them like family, friends and health professionals (50). According to the results of this study, relationships can be both facilitators and inhibitors of empowerment, and patient's skills play an important role in managing these relationships. Relationships mixed with pity, contempt, and labeling patient can have an inhibiting effect, and instead of negative coping mechanisms that were found in this study, patients require skills to properly and decisively deal with these types of relationships. Relationship with the medical team was also important to patients. Relationship with spouse and sexual relationship are the key issues in quality of life (71), and changes in sexual health can be the biggest problem of patients with breast cancer (72), which may continue for years after treatment (73, 74). These changes had caused feelings of inability and helplessness in majority of participants to establish a satisfying relationship. This feeling of inability can be due to the fact that in view of most women, sexual relationship has a limited definition and interpretation, and now with lack of a breast, vaginal dryness, pain, and such problems has harmed their relationship and made them incapable. For empowerment in this area, women require information about preserving their sexual relationship with a variety of love making skills and intimacy and ways to improve sexual problems. Usually, there are no specific sources to receive this type of information. In a study by Li (2011), sexual information, compared to other information needs, such as diagnosis, and progress of the disease and treatment had much priority (75). In a study by Jane a large number of women also needed sexual information, but nearly $2 / 3$ of them had not received this information because they did not know where to go to receive this information, and their sexual needs had been marginalized (76). Perhaps, these reasons had affected silencing of patients' needs for sexual information. Additionally, cultural reasons could also be involved. Because talking about sexual issues and related subjects are not common in the Iranian culture, the majority of patients shy away from such debates. In this study, participants did not even talk to their spouse about these problems. In a study in Japan, the need for information about sexual changes caused by breast cancer treatments and sexual relationships, was reported the most important information need for these women, while only $10 \%$ of the participants had received counseling in this regard, and this counseling was initially with their friends (77), while providing this information by health experts can reduce distress associated with sexual changes (78). Relationship with groups and peers was another influencing factor on empowerment in this study. According to some studies, these groups can cause improvement in empowerment (15, 79-81). The basis in peer-support groups is provision of mutual help and support by patients (82). The benefits of peer groups include sharing experiences (83), comparing one another in similar circumstances (84), and feeling less lonely (85). Information exchange (86), helping others and resulting mental health (87) all help empower patients.

Participants that used the internet obtained their information in this way. Kuijpers et al. showed that the internet and intervention through the internet has beneficial effects on empowerment of patients with chronic diseases (88). In a study by Hoybye et al. the internet was a means of information and experience exchange among women with breast cancer and also a means for finding strategies of living with cancer (89). Although breast cancer is the most common type of cancer among women worldwide, including in Iran, where mean age at diagnosis is ten years lower than that in Western countries, empowerment of relatively young women appears highly imperative. However, this study was conducted in Iran for the first time, and it seems the non-structured and in-depth interviews and prolonged communication of a researcher with the participants have produced reliable data, which can lead to more valid results. This study was conducted in the city of Isfahan, where despite similarity to other places in Iran, it was limited in generalization of the results (like other qualitative studies), and thus it is necessary to repeat the study in other locations with different cultural backgrounds. Moreover, it is recommended that role of factors obtained in this study be examined experimentally and interventionally in empowerment of women with breast cancer in future studies.

Empowerment is an essential need of women with breast cancer and the medical team has a major role in providing and facilitating this need. To provide this, factors found in this and in similar studies that explain empowerment needs from patients' experiences should be considered and used when treating these patients and in education and counseling programs.

\section{Acknowledgements}

I would like to thank all of the women with breast cancer participated in this study. In addition, we gratefully acknowledge the financial support of this study by the Isfahan University of Medical Sciences.

\section{References}

1. Jemal A, Siegel R, Xu J, Ward E. Cancer statistics, 2010. CA Cancer J Clin. 2010;60(5):277-300.

2. Kolahdoozan S, Sadjadi A, Radmard AR, Khademi H. Five common cancers in Iran. Arch Iran Med. 2010;13(2):143-6.

3. Harirchi I, Karbakhsh M, Kashefi A, Momtahen AJ. Breast cancer in Iran: results of a multi-center study. Asian Pac J Cancer Prev. 2004;5(1):24-7.

4. Taleghani F, Yekta ZP, Nasrabadi AN. Coping with breast cancer in newly diagnosed Iranian women. J Adv Nurs. 2006;54(3):265-72.

5. American Cancer Society . Cancer Facts \& Figures 2012. 2012:11.

6. Wonghongkul T, Dechaprom N, Phumivichuvate L, Losawatkul S. Uncertainty appraisal coping and quality of life in breast cancer survivors. Cancer Nurs. 2006;29(3):250-7.

7. Brandberg Y, Sandelin K, Erikson S, Jurell G, Liljegren A, Lindblom A, et al. Psychological reactions, quality of life, and body image 
after bilateral prophylactic mastectomy in women at high risk for breast cancer: a prospective 1-year follow-up study. J Clin Oncol.2008;26(24):3943-9.

8. Tel H, Doğan S. Fatigue, anxiety and depression in cancer patients. Neurol Psychiat BR. 2011;17(2):42-5.

9. Beaulac SM, McNair LA, Scott TE, LaMorte WW, Kavanah MT. Lymphedema and quality of life in survivors of early-stage breast cancer. Arch Surg. 2002;137(11):1253-7.

10. Vazquez-Calatayud M, Carrascosa-Gil R, Vivar CG. [The transitional survivorship in breast cancer: a narrative review]. Rev Enferm. 2010;33(10):30-9.

11. Kucukkaya PG. An exploratory study of positive life changes in Turkish women diagnosed with breast cancer. Eur J Oncol Nurs. 2010;14(2):166-73.

12. Lauzier S, Maunsell E, Levesque P, Mondor M, Robert J, Robidoux A, et al. Psychological distress and physical health in the year after diagnosis of DCIS or invasive breast cancer. Breast Cancer Res Treat. 2010;120(3):685-91.

13. Yoon J, Malin JL, Tisnado DM, Tao ML, Adams JL, Timmer MJ, et al. Symptom management after breast cancer treatment: is it influenced by patient characteristics? Breast Cancer Res Treat. 2008;108(1):69-77.

14. Gray RE, Doan BD, Church K. Empowerment and persons with cancer: politics in cancer medicine. J Palliat Care.1990;6(2):33-45.

15. Mok E, Martinson I. Empowerment of Chinese patients with cancer through self-help groups in Hong Kong. Cancer Nurs. 2000;23(3):206-13.

16. Nystrom AE, Segesten KM. On sources of powerlessness in nursing home life. J Adv Nurs. 1994;19(1):124-33.

17. Fisher MI, Howell D. The power of empowerment: An ICF-based model to improve self-efficacy and upper extremity function of survivors of breast cancer. Rehabil Oncol. 2010;28(3):19-25.

18. Tobacco control Research Report. . Youth Empowerment and Health Promotion. 1999. Available from: http://www.ftcc.fsu.edu/ resreports/july99/index.html/.

19. Hibbard JH, Stockard J, Mahoney ER, Tusler M. Development of the Patient Activation Measure (PAM): conceptualizing and measuring activation in patients and consumers. Health Serv Res. 2004;39(4 Pt1):1005-26.

20. Roberts KJ. Patient empowerment in the United States: a critical commentary. Health Expect. 1999;2(2):82-92.

21. Chavasse JM. New dimensions of empowerment in nursing--and challenges. J Adv Nurs. 1992;17(1):1-2.

22. Nute R, Robinson T. Standard empowering people with diabetes. Primary Health Care. 2004;14(2):35-7.

23. Shiu AT, Wong RY, Thompson DR. Development of a reliable and valid Chinese version of the diabetes empowerment scale. Diabetes Care. 2003;26(10):2817-21.

24. Anderson RM, Funnell MM. Patient empowerment: reflections on the challenge of fostering the adoption of a new paradigm. Patient Educ Couns. 2005;57(2):153-7.

25. Bodenheimer T, Lorig K, Holman H, Grumbach K. Patient self-management of chronic disease in primary care. JAMA. 2002;288(19):2469-75.

26. Neuhauser D. The coming third health care revolution: personal empowerment. Qual Manag Health Care. 2003;12(3):171-84.

27. Koch T, Jenkin P, Kralik D. Chronic illness self-management: locating the 'self'. J Adv Nurs. 2004;48(5):484-92.

28. Zimmerman MA. Empowerment theory: psychological, organizational and community levels of analysis. In: Rapaport J, Seldman E editors. Handbook of Community Psychology.. New York: Plenum; 2000. pp. 43-63.

29. Sue DW, Sue D. 5 ed. New York: NY: Wiley; 2007.

30. Guadagnoli E, Ward P. Patient participation in decision-making. Soc Sci Med.1998;47(3):329-39.

31. Funnell MM, Anderson RM. Patient empowerment: a look back, a look ahead. Diabetes Educ. 2003;29(3):454-8-462 passim.

32. Aujoulat I, d'Hoore W, Deccache A. Patient empowerment in theory and practice: polysemy or cacophony? Patient Educ Couns. 2007;66(1):13-20.

33. Aujoulat I, Marcolongo R, Bonadiman L, Deccache A. Reconsidering patient empowerment in chronic illness: a critique of models of self-efficacy and bodily control. Soc Sci Med.
2008;66(5):1228-39.

34. Lorig KR, Holman H. Self-management education: history, definition, outcomes, and mechanisms. Ann Behav Med. 2003;26(1):1-7.

35. Lorig K, Ritter PL, Villa FJ, Armas J. Community-based peer-led diabetes self-management: a randomized trial. Diabetes Educ. 2009;35(4):641-51.

36. Gibson $\mathrm{CH}$. The process of empowerment in mothers of chronically ill children. J Adv Nurs. 1995;21(6):1201-10.

37. Anderson RM, Funnell MM. Patient empowerment: myths and misconceptions. Patient Educ Couns. 2010;79(3):277-82.

38. Funnell MM, Anderson RM, Arnold MS, Barr PA, Donnelly M, Johnson PD, et al. Empowerment: an idea whose time has come in diabetes education. Diabetes Educ.1991;17(1):37-41.

39. Hagiwara E, Futawatari T. A Concept analysis: Empowerment in cancer patients. Kitakanto Med J. 2013;63(2):165-74.

40. Bulsara C, Ward A, Joske D. Haematological cancer patients: achieving a sense of empowerment by use of strategies to control illness. J Clin Nurs. 2004;13(2):251-8.

41. Broom A. Virtually he@lthy: the impact of internet use on disease experience and the doctor-patient relationship. Qual Health Res. 2005;15(3):325-45.

42. Gibson $\mathrm{CH}$. A concept analysis of empowerment. J Adv Nurs. 1991;16(3):354-61.

43. Parvizi S, Ghasemzadeh-Kakroodi F, Fatemi N, Nasseri F. Social factors contributing in women health in Tehran city: A qualitative study. Iran J Nurs Res. 2010;4(15).

44. Streubert HJ, Carpenter DR. Qualitative research in nursing: Advancing the humanistic imperative. 4 edPhiladelphia: Lippincott Williams \& Wilkins; 2007

45. Guba EG. Criteria for assessing the trustworthiness of naturalistic inquiries. Edu Com Tech J.1981;29(2):75-91.

46. Lincoln YS. Emerging Criteria for Quality in Qualitative and Interpretive Research. Qualitative Inquiry. 1995;1(3):275-89.

47. Roglic G, Unwin N, Bennett PH, Mathers C, Tuomilehto J, Nag S, et al. The burden of mortality attributable to diabetes: realistic estimates for the year 2000. Diabetes Care. 2005;28(9):2130-5.

48. Gould J, Grassau P, Manthorne J, Gray RE, Fitch MI. 'Nothing fit me': nationwide consultations with young women with breast cancer. Health Expect. 2006;9(2):158-73.

49. Paterson B. Myth of empowerment in chronic illness. J Adv Nurs. 2001;34(5):574-81.

50. Mok E, Martinson I, Wong TK. Individual empowerment among Chinese cancer patients in Hong Kong. West J Nurs Res. 2004;26(1):59-75

51. Mok E. Empowerment of cancer patients: from a Chinese perspective. Nurs Ethics. 2001;8(1):69-76.

52. Morris EL. The relationship of spirituality to coronary heart disease. Altern Ther Health Med. 2001;7(5):96-8.

53. Larson C. A. . . Spiritual Psycholosocial and physical correlates of well-being across the breast cancer experience .. Arizona: The University of Arizona; 2004.

54. Meraviglia M. Effects of spirituality in breast cancer survivors. Oncol Nurs Forum. 2006;33(1):E1-7.

55. Schulz E, Holt CL, Caplan L, Blake V, Southward P, Buckner A, et al. Role of spirituality in cancer coping among African Americans: a qualitative examination. J Cancer Surviv. 2008;2(2):104-15.

56. Romero C, Friedman LC, Kalidas M, Elledge R, Chang J, Liscum KR. Self-forgiveness, spirituality, and psychological adjustment in women with breast cancer. J Behav Med. 2006;29(1):29-36.

57. Cotton SP, Levine EG, Fitzpatrick CM, Dold KH, Targ E. Exploring the relationships among spiritual well-being, quality of life, and psychological adjustment in women with breast cancer. Psychooncology. 1999;8(5):429-38.

58. Bussing A, Matthiessen PF, Ostermann T. Engagement of patients in religious and spiritual practices: confirmatory results with the SpREUK-P1.1 questionnaire as a tool of quality of life research. Health Qual Life Outcomes. 2005;3:53.

59. Gordon HS, Street RJ, Sharf BF, Kelly PA, Souchek J. Racial differences in trust and lung cancer patients' perceptions of physician communication. J Clin Oncol. 2006;24(6):904-9.

60. Keating NL, Gandhi TK, Orav EJ, Bates DW, Ayanian JZ. Patient characteristics and experiences associated with trust in specialist physicians. Arch Intern Med. 2004;164(9):1015-20. 
61. Keating NL, Green DC, Kao AC, Gazmararian JA, Wu VY, Cleary PD How are patients' specific ambulatory care experiences related to trust, satisfaction, and considering changing physicians? J Gen Intern Med. 2002;17(1):29-39.

62. Fiscella K, Meldrum S, Franks P, Shields CG, Duberstein P, McDaniel SH, et al. Patient trust: is it related to patient-centered behavior of primary care physicians? Med Care. 2004;42(11):1049-55.

63. Arora NK, Gustafson DH. Perceived helpfulness of physicians communication behavior and breast cancer patients' level of trust over time. J Gen Intern Med. 2009;24(2):252-5.

64. Paterson B, Thorne S, Crawford J, Tarko M. Living with Diabetes as a Transformational Experience. Qual Health Res. 1999;9(6):786802.

65. Stanhope M, Lancaster J. Community and public health nursing.Philadelphia: Mosby; 2004.

66. McWilliam C, Stewart M, Brown JB, McNair S, Desai K, Patterson $\mathrm{ML}$, et al. Creating empowering meaning: an interactive process of promoting health with chronically ill older Canadians. Health Promot Int. 1997;12(2):111-23.

67. Emanuel EJ, Emanuel LL. Four models of the physician-patient relationship. JAMA.1992;267(16):2221-6.

68. Bandura A. Health promotion from the perspective of social cognitive theory. Psy and Health.1998;13(4):623-49.

69. Northouse LL, Mood D, Kershaw T, Schafenacker A, Mellon S, Walker J, et al. Quality of life of women with recurrent breast cancer and their family members. J Clin Oncol. 2002;20(19):4050-64.

70. Cunningham AJ, Lockwood GA, Cunningham JA. A relationship between perceived self-efficacy and quality of life in cancer patients. Patient Educ Couns. 1991;17(1):71-8.

71. Krebs LU. Sexual assessment in cancer care: concepts, methods, and strategies for success. Semin Oncol Nurs. 2008;24(2):80-90.

72. Gilbert E, Ussher JM, Perz J. Sexuality after breast cancer: a review. Maturitas. 2010;66(4):397-407.

73. Berter C, Wilmoth MC. Breast cancer diagnosis and its treatment affecting the self : a meta-synthesis. Cancer Nurs. 2007;30(3):194202.

74. Andersen BL. In sickness and in health: maintaining intimacy after breast cancer recurrence. Cancer J. 2009;15(1):70-3.

75. Li PW, So WK, Fong DY, Lui LY, Lo JC, Lau SF. The information needs of breast cancer patients in Hong Kong and their levels of satisfaction with the provision of information. Cancer Nurs. 2011;34(1):49-57.

76. Ussher JM, Perz J, Gilbert E. Information needs associated with changes to sexual well-being after breast cancer. $J$ Adv Nurs. 2013;69(2):327-37.

77. Takahashi M, Ohno S, Inoue H, Kataoka A, Yamaguchi H, Uchida $\mathrm{Y}$, et al. Impact of breast cancer diagnosis and treatment on women's sexuality: a survey of Japanese patients. Psychooncology. 2008;17(9):901-7.

78. Ayaz S, Kubilay G. Effectiveness of the PLISSIT model for solving the sexual problems of patients with stoma. J Clin Nurs. 2009;18(1):89-98.

79. Ussher J, Kirsten L, Butow P, Sandoval M. What do cancer support groups provide which other supportive relationships do not? The experience of peer support groups for people with cancer Soc Sci Med. 2006;62(10):2565-76.

80. Sharf BF. Communicating breast cancer on-line: support and empowerment on the Internet. Women Health.1997;26(1):65-84.

81. Gray R, Fitch M, Davis C, Phillips C. A qualitative study of breast cancer self-help groups. Psychooncology. 1997;6(4):279-89.

82. Borkman T. Understanding Self-help/mutual Aid: Experiential Learning in the Commons.: Rutgers University Press; 1999.

83. Bruin J, Ventevogel A. Patiëntencommunities op het web: theorie en praktijk.Amsterdam:VU uitgeverij; 2007.

84. Campbell HS, Phaneuf MR, Deane K. Cancer peer support programs-do they work? Patient Educ Couns. 2004;55(1):3-15.

85. Oudenampsen D, Nederland T, Kromontono E, Pepels R Sonneveld R, Stilstette M. Patienten-en Consumentenbeweging in Beeld: brancherapport 2006. Utrecht. 2007.

86. Masi CM, Suarez-Balcazar Y, Cassey MZ, Kinney L, Piotrowski ZH Internet access and empowerment: a community-based health initiative. J Gen Intern Med. 2003;18(7):525-30.

87. Riessman F. Ten self-help principles. Social Policy. 1997;27:6-11.

88. Kuijpers W, Groen WG, Aaronson NK, van Harten WH. A systematic review of web-based interventions for patient empowerment and physical activity in chronic diseases: relevance for cancer survivors. J Med Internet Res. 2013;15(2).

89. Hoybye MT, Johansen C, Tjornhoj-Thomsen T. Online interaction. Effects of storytelling in an internet breast cancer support group. Psychooncology. 2005;14(3):211-20. 